\title{
ATRA-Daunorubicin Regimen
}

National Cancer Institute

\section{Source}

National Cancer Institute. ATRA-Daunorubicin Regimen. NCI Thesaurus. Code C63599.

A regimen consisting of tretinoin (all-trans retinoic acid or AT RA) and daunorubicin used as an induction treatment for acute promyelocytic leukemia (APL). 